\title{
A descriptive study about the use of pillboxes by older adults
}

\author{
Frank Roger Defanti e Souza*, Carla da Silva Santana
}

Bio-Engineering Inter-Unit Program, University of São Paulo, São Carlos, Brazil;

*Corresponding Author: frogerdefanti@gmail.com

Received 15 October 2013; revised 15 November 2013; accepted 28 November 2013

Copyright (C 2013 Frank Roger Defanti e Souza, Carla da Silva Santana. This is an open access article distributed under the Creative Commons Attribution License, which permits unrestricted use, distribution, and reproduction in any medium, provided the original work is properly cited.

\begin{abstract}
The goal of this research was to observe which features, according to the users' point of view, might influence the use of pillboxes. Older adults were surveyed in order to test different pillboxes and report their observations about their difficulties. Both the individuals and the pillboxes themselves have characteristics that might influence successful use, such as difficulty remembering medication names and lack of hand strength and the complexity of the pillboxes' alarm system and opening mechanism. Pillboxes can be effective in helping older adults take their medication provided they are designed according to both dosage prescription and the user's functional capacity.
\end{abstract}

Keywords: Aging; Medication Adherence; Self-Help Devices

\section{INTRODUCTION}

The failure to follow a medication regimen can result in serious medical outcomes for the patients and significantly increase health costs [1,2]. Indeed, 33\% - 69\% of medication-related hospital admissions have been found to be due to the weak medication adherence [1-5]. Patients' errors that lead to adverse drug events have been found to be often related to adherence errors [6-8]. The higher rates of medication-related hospital admissions are associated with elderly patients prescribed with a multidrug regimen $[1,4,6]$

Measuring adherence rates accurately is a very difficult task [8-11]. Estimates of adherence rates in elderly populations range from $27.8 \%$ to $75 \%$ [12]. Adherence rates have been found to deteriorate with increasing length of time on a medication regimen [10] and with the amount and variety of medications routinely taken [12]. Older adults are more liable to bear the multiple chronic illness $[13,14]$ that commonly involve the prescription of multiple long-term medications [15-17] and such intricate regimens have been associated to a greater possibility of non-adherence $[1,15,18]$. Moreover, age-related changes in cognition increase the complexity of this task. These cognitive declines, that often accompany aging, may include losses in the working memory and other executive functions, may decrease the ability of those individuals to successfully assimilate and execute their prescribed medication regimens $[2,11,19]$, and those, when combined with the physiological declines and shown up as distinctive pharmacokinetics and pharmacodynamics, result in a greater risk of adverse drug reactions [15,20].

There are a handful of versatile solutions to improve the medication adherence by older adults, the pillbox being one of the most largely used methods [21-24]. There are a vast quantity of different pillboxes, the most common being one with a weekly format with four sub-compartments corresponding to different periods of the day (Morning, Noon, Evening, and Bed Time) [22,23]. Pillboxes were developed to decrease adherence errors and allow the elderly to maintain an independent lifestyle [8, 22-25]. But filling correctly the pillbox is not a simple task as it requires an understanding of complex medication regimens, in addition to the skill to organize a schedule with the prescriptions and handle this schedule across a one-week timeframe [2,21]. Some recent studies have found that, while using pillboxes, only $53 \%$ to $68.1 \%$ of the older adults adhered correctly to their prescribed regimens $[9,12,21]$. These errors made while using a pillbox, including putting the pills in the wrong compartment or taking a pill from the wrong compartment, are dangerous because they are likely to be perpetuated throughout the entire week [21].

In a recent study, pillboxes were found to be widely used through the Canadian elderly population, but it was 
observed that the types of pillboxes chosen and the ways in which they were used may not be optimal to ensure the medication adherence and prevent adherence errors [21]. Additionally, there is a lack of research on the effects of the inherent ergonomic characteristics of the pillboxes, other than the opening mechanism, which could influence their use by the older adults, making it easier or harder to stand this complex task [2].

The goal of this study was to describe the different attributes that may turn the use of pillboxes easier or harder for the older adults, while also noting if there are any personal characteristics of this population that may also influence over the adherence to the medication regimen while using pillboxes. Knowing these factors could help us to answer the following questions: Are difficulties in using the pillboxes related to the user, the device or both? And what could be done to make the pillboxes more effective in helping the older adults to have a better adherence to their medication regimens?

\section{METHODS}

\subsection{Participants}

One hundred seniors were randomly contacted in the waiting rooms of the Ribeirão Preto Clinics Hospital, located at Ribeirão Preto, São Paulo-Brazil. Within this sample, 18 participant refusals occurred at the initial recruitment stage. The final sample included 82 individuals, consisting of 26 males and 56 females.

\subsection{Interventions}

This study was conducted from January of 2009 to January of 2010. The data collection tool included two surveys directed to senior adults living in Ribeirão Preto, Brazil. The first survey contained the following questionnaires: A demographic questionnaire, the MiniMental State Examination, the Lawton and Brody's Instrumental Activity of Daily Living Scale, and a modified version of the MedTake Test, in which two questions were added to the original test, asking about the price of the medicine and who covers its costs [26].

In the demographic questionnaire, participants were asked to self-report their gender, age, and educational attainment. They were also asked to rate their health on a scale ranging from excellent to poor and to report any medical conditions they had at the moment. In the modified MedTake Test, participants were asked to self-report any medications being taken (prescribed or over-thecounter), including its names, prescribed doses, form of ingestion, the price of each medicine and who covers its costs.

For the second survey, from the total sample $(\mathrm{n}=82)$ a new group of participants was constituted $(n=20)$. The goal of this second survey was to test different pillboxes and observe and describe any characteristic that may influence their use by the older adults, in the opinion of the users.

To be included in this new group, the older adults had to be independent in managing their medications, show no cognitive deficit, and agree to test a pillbox and be monitored by phone calls daily for a period of two weeks. The participants tested pillboxes that were previously chosen by the researchers based on their prescriptions (the quantity of drugs taken by each subject). Individually to each participant, it was explained how the pillbox worked and how the medicines should be distributed in it. Participants received daily morning phone calls to ascertain the difficulties encountered in the use of the pillbox and this phone call also functioned as a reminder to take the drug, thus preventing the inclusion of the pillbox in their routines from compromising the achievement of the task.

At the end of the trial period, in a face-to-face interview using a structured questionnaire, the participants evaluated the pillbox they tested in regard to its ergonomic aspects and their own personal characteristics that may influenced the use of the pillboxes, they also reported their personal opinion about the effectiveness of the pillboxes in helping them in terms of organizing the task of managing their medications.

This study was approved by the Ribeirão Preto Clinics Hospital's Research Ethics Board.

\subsection{Data Analysis}

Descriptive statistics were used to describe the data collected into both surveys.

\subsection{Pillboxes}

The pillboxes that were tested in this study, shown in Table 1, were chosen based on the following factors: an individual cost that ranged between US\$ 2.00 and US\$ 30.00 , availability in the Brazilian stores, pharmacies and/or on the Internet, and suitability considering the posology, dosage and number of tablets to be taken by each subject. The quantity of medication that each pillbox was able to hold was noted and they were selected to cover several possible medication prescriptions. The researchers also sought to include among the devices those which had unique characteristics, such as a security lock or alarm system. These characteristics are also indicated in Table 1.

\section{RESULTS}

\subsection{Sample Characteristics}

A total of one hundred seniors were contacted randomly, within this sample 18 participant refusals oc- 
Table 1. Pillboxes selected for the two week test period.

\begin{tabular}{|c|c|c|}
\hline Pillbox & $\begin{array}{l}\text { Product Name } \\
\text { (Producer) }\end{array}$ & Characteristics \\
\hline Pillbox 1 & $\begin{array}{l}\text { Pillbox G-Life } 1000 \\
\text { (G-Life })\end{array}$ & $\begin{array}{c}\text { Digital alarm; } \\
\text { LCD display; } \\
\text { Two sub-compartments. }\end{array}$ \\
\hline Pillbox 2 & $\begin{array}{l}\text { Pillbox G-Life } 2000 \\
\text { (G-Life })\end{array}$ & $\begin{array}{l}\text { Weekly organizer with divisions } \\
\text { per period of the day }(7 \times 4) \text {; } \\
\text { Individual modules (daily doses) } \\
\text { that can be separated and taken } \\
\text { away when out of home. }\end{array}$ \\
\hline Pillbox 3 & $\begin{array}{l}\text { Pillbox G-Life } 6000 \\
\text { (G-life) }\end{array}$ & $\begin{array}{c}\text { Pill-cutter blade; } \\
\text { Two sub-compartments (Daily } \\
\text { doses) that can be separated } \\
\text { and taken away when out of home. }\end{array}$ \\
\hline Pillbox 4 & $\begin{array}{l}\text { Bioland } 201 \\
\text { (Bioland) }\end{array}$ & $\begin{array}{l}\text { Seven compartments; } \\
\text { Digital programmable sound } \\
\text { alarm; LCD display. }\end{array}$ \\
\hline Pillbox 5 & $\begin{array}{l}\text { Bioland 202V } \\
\text { (Bioland) }\end{array}$ & $\begin{array}{l}\text { Seven compartments; } \\
\text { Digital programmable sound } \\
\text { \& vibration alarm; } \\
\text { LCD display. }\end{array}$ \\
\hline Pillbox 6 & $\begin{array}{c}\text { Pillbox "Hora-Certa" } \\
\text { (Serraplas) }\end{array}$ & $\begin{array}{l}\text { Weekly organizer with divisions } \\
\text { per period of the day }(7 \times 4) \text {; } \\
\text { Day indications in Braille language; } \\
\text { Security locks. }\end{array}$ \\
\hline Pillbox 7 & $\begin{array}{l}\text { Pocket Pill Case } \\
\text { (Look Vision) }\end{array}$ & Seven compartments. \\
\hline Pillbox 8 & $\begin{array}{l}\text { Pillbox } \\
\text { (Plasútil) }\end{array}$ & Seven compartments. \\
\hline
\end{tabular}

curred. The final sample for the first survey included 82 participants, consisting of 26 males and 56 females. The social characteristics of the sample are shown in Table 2. The sample reported having on average 2.47 chronic conditions. Men reported an average of two chronic diseases while women reported 2.69. The minimum observed was one disease and the maximum was eight diseases. High blood pressure (24.2\%), diabetes (9.5\%) and osteoporosis (8.4\%) were the most common reported diseases. And even then, half of the sample classified their health status as Good (50\%).

The sample's reported ability to perform the Instrumental Activities of Daily Living was mostly preserved (63.4\%), including the ability to manage their medications (92.7\%) and, according to the Mini-Mental State Examination, most of them (93.9\%) had no cognitive impairment.

Table 3 shows the older adults' knowledge about their ongoing medications, their self-reported health status and diseases.

Regarding the quantity of drugs ingested daily, $62.2 \%$ of them took one to four medicines, $25.6 \%$ took five to eight medicines and $12.2 \%$ took nine to 12 medicines. It was observed that men took a mean of 3.8 medications and women took 4.5 medications. $30.5 \%$ pay for their
Table 2. Characteristics of the participants $(n=82)$ including demographic aspects, mental status and functional capacity.

\begin{tabular}{cc}
\hline Characteristic & Result \\
\hline Age & $\mathbf{( \% )}$ \\
Range & $60-87$ \\
$60-70$ years & $51(62.2)$ \\
Over 70 years & $31(37.8)$ \\
Education & $\mathbf{( \% )}$ \\
$1-7$ years & $53(64.6)$ \\
8 years or more & $27(33.0)$ \\
Mental Status & $\mathbf{( \% )}$ \\
Male & \\
Maintained & $23(88.5)$ \\
Cognitive impairment & $3(11.5)$ \\
Female & \\
Maintained & $54(96.4)$ \\
Cognitive impairment & $2(3.6)$ \\
Functional capacity & $\mathbf{( \% )}$ \\
Male & \\
Independent performing all IADLs & $9(34.6)$ \\
Independent at medication-taking & $22(84.6)$ \\
Female & \\
Independent performing all IADLs & $43(79.6)$ \\
Independent at medication-taking & $54(96.4)$ \\
\hline
\end{tabular}

Table 3. Reported diseases, knowledge of the medication prescribed and health status reported.

\begin{tabular}{|c|c|c|c|c|}
\hline Reported medical problems & \multicolumn{2}{|c|}{$\mathbf{n}$} & \multicolumn{2}{|c|}{$\%$} \\
\hline High blood pressure & \multicolumn{2}{|c|}{46} & \multicolumn{2}{|c|}{24.2} \\
\hline Diabetes & \multicolumn{2}{|c|}{18} & \multicolumn{2}{|c|}{9.5} \\
\hline Osteoporosis & \multicolumn{2}{|c|}{16} & \multicolumn{2}{|c|}{8.4} \\
\hline Heart problems & \multicolumn{2}{|c|}{15} & \multicolumn{2}{|c|}{7.9} \\
\hline Hypothyroidism & \multicolumn{2}{|c|}{13} & \multicolumn{2}{|c|}{6.8} \\
\hline $\begin{array}{l}\text { Arthritis/Rheumatoid } \\
\text { arthritis/Arthrosis }\end{array}$ & \multicolumn{2}{|c|}{11} & \multicolumn{2}{|c|}{5.8} \\
\hline Mood disorders & \multicolumn{2}{|c|}{10} & \multicolumn{2}{|c|}{5.3} \\
\hline Eye problems & \multicolumn{2}{|c|}{9} & \multicolumn{2}{|c|}{4.7} \\
\hline Stomach problems & \multicolumn{2}{|c|}{7} & \multicolumn{2}{|c|}{3.7} \\
\hline Labyrinthitis & \multicolumn{2}{|c|}{5} & \multicolumn{2}{|c|}{2.6} \\
\hline Others & \multicolumn{2}{|c|}{40} & \multicolumn{2}{|c|}{21.1} \\
\hline Knowledge on medication & \multicolumn{2}{|c|}{ Know } & \multicolumn{2}{|c|}{ Don't know } \\
\hline$(n=82)$ & $\mathbf{n}$ & $\%$ & $\mathbf{n}$ & $\%$ \\
\hline Name & 71 & 86.6 & 11 & 13.4 \\
\hline Form of ingestion & 79 & 96.3 & 3 & 3.7 \\
\hline Dose prescribed & 65 & 79.3 & 17 & 20.7 \\
\hline Individual price & 25 & 30.5 & 57 & 69.5 \\
\hline Indication & 74 & 90.2 & 8 & 9.8 \\
\hline Reported health status & \multicolumn{2}{|c|}{$\mathbf{n}$} & \multicolumn{2}{|c|}{$\%$} \\
\hline Excellent & \multicolumn{2}{|c|}{8} & \multicolumn{2}{|c|}{9.8} \\
\hline Good & \multicolumn{2}{|c|}{41} & \multicolumn{2}{|c|}{50.0} \\
\hline Fair & \multicolumn{2}{|c|}{27} & \multicolumn{2}{|c|}{32.9} \\
\hline Poor & \multicolumn{2}{|c|}{6} & & \\
\hline
\end{tabular}


own medication, $36.6 \%$ shared the cost with just the Brazilian Unified Health System, 11\% of participants received financial assistance from a family member to acquire at least one of their medicines and $2.4 \%$ of the participants did not known who paid for their drugs. It was identified that $20.7 \%$ of the sample did not know the prescribed dose of their medications. 39\% of the sample reported forgetting to take at least one of their medications quite often before they started using a pillbox.

\subsection{Pillboxes Trial Period Collected Data}

After the test period, participants were asked to report if the pillboxes they used were suitable for their needs and if they believe that the pillboxes were useful in helping them manage their medication. This statement was based on the personal vision of each participant about the pillbox that they used in the trial period, thus 95\% of the sample considered their pillbox suitable for their needs. One reason why a pillbox could be inadequate for the prescribed dosage is because the available space in pillboxes compartments is limited, leaving little room to store the user's medication, as one participant reported, her tablets did not fit in the device's compartments.

In terms of efficacy in helping to manage their medicines, $85 \%$ of participants reported that the device was useful. The most common benefit reported was being able to easily check whether the medicine had already been taken or not, thus avoiding the risk of taking it twice or not taking it at all. These participants were interested in continuing to use the pillboxes because, according to them, they had been useful for helping organizing their medication. Those participants also considered recommending the pillbox to others as they believed that it could help other older adults to manage their medications on an independent basis.

During the trial period, the participants were requested to report any personal characteristics (memory, muscular strength, visual acuity) or device related characteristics (size, shape) that they believe may have influenced the use of the pillboxes.

Regarding the personal characteristics, one participant reported to have a small intention tremor and difficulty picking up tablets (poor handgrip) and two reported decreased strength in their hands.

Regarding the device related characteristics, the participants reported that there was little space available inside the pillboxes to collect the pills and this, coupled with the motor difficulty of some of the participants have made it necessary to turn the whole pillbox on their palm, over a table or a counter in order to find a better grip, but this meant that if the pillbox had only one lid over all of the compartments then the different days' tablets would fall out and become mixed up. Also, some pillboxes
(Pillboxes: 4, 5, 7 and 8) had a lack of contrast between letters and background (container color), an inadequate opening/closing mechanism that was making it too hard to open or to close the device (Pillboxes: 2, 4 and 5). Those characteristics allowed some of the users to feel a lack of security when using the pillboxes during the trial period.

Two of the pillboxes (Pillboxes: 2 and 6) proposed a division of medicines between the different periods of the day, however the users indicated a lack of a separation between the medications to be taken before breakfast and those to be taken after eating breakfast.

Some of the pillboxes (Pillboxes: 4 and 5) had included an electronic alarm system which aimed to facilitate the administration of medicines, but the users reported that most of those alarm systems found to be difficult to operate, with the alarm being triggered outside of the scheduled time and the electronic display screen being too small to be viewed by the older adults and used to configure systems. These devices also had small and hard-to-press buttons. Pillbox 1, which had a simpler alarm system and improved accessibility, was highly rated and accepted by the users.

With regard to safety, one of the devices (Pillbox 2) had no system stopping the compartments falling out and the tablets becoming disorganized, despite these being designed to be withdrawn from the base and properly positioned for the user. Also, because the compartments were not differentiated, they could be wrongly placed on the base which indicated the day of the week, thus confusing the user about which medication had or had not previously been taken. Moreover, the ink that indicates the day of the week and the period of the day had worn off after two weeks of use, erasing some of the indicators. The fact that Pillbox 3 contained a razor blade to facilitate the splitting of tablets was considered very useful by the participants.

After the trial period, if the participant expressed a positive opinion on the pillbox and wanted to keep it, he or she was allowed to do so. At the end of the study $85 \%$ of the participants showed interest in continuing to use their pillboxes and reported that this decision was based on the feeling that the pillbox was shown to be useful for organizing their medication. Those participants also considered recommending these pillboxes to others as they believed that it could help other older adults to take their medications on an independent basis. On the other hand, Pillbox 4 and 5, which had complex alarm systems and small display screens, were very unlikely to be recommended by the participants.

\section{DISCUSSION}

Previous studies have suggested that seniors' ability to take oral prescription drugs safely is affected by cogni- 
tive function and socioeconomic status [2,26], health knowledge, and health and medication habits [8,27]. In addition, studies have suggested that special attention should be paid to persons taking three or more drugs, living alone, and receiving drugs from multiple doctors, as well as to those with pre-dementia symptoms, as they are at higher risk of non-adherence $[2,21,25,28]$.

In the sample studied, even though almost all of the older adults reported independence in administration of their medicines (92.7\%), it was identified that $20.7 \%$ of them did not know the prescribed dose of at least one of their medications, a situation that can bring health risks to these individuals. Most of the sample could state their medication name and form of ingestion, although some of them could not talk about its buying cost. In general, one of their family members bought their medications and they did not personally visit the pharmacy to buy it. A great number of participants said "I can get this medication for free”, indicating that they used a medication dispensed from a public pharmacy, so they indirectly pay for it, but believe it to be free.

Overall, we found that $85 \%$ of the sample reported that the pillbox they tested helped them manage their medications. The most commonly cited benefit was being able to easily check whether the medicine had already been taken, thus avoiding the risk of taking it twice. A Canadian study showed that only $2 \%$ of the elderly sample reported their pillbox as having no overall effectiveness in helping them take medications correctly $[21,29]$. The same study also found that $86.9 \%$ and $91.8 \%$ of the sample replied that the pillboxes were useful for remembering the time and day of dosage and useful for remembering the correct amount respectively $[21,29]$. In a literature review on the efficacy of using pillboxes in adhering to drug treatment, most of these studies pointed positive results [30]. However, in order to assess the reliability of the results regarding the influence of the pillboxes, the duration of follow-up and sample size need to be taken into account, as well as the diversity of the methodological design of these studies [30].

A study that tested the use of pillboxes by 245 people with Acquired Immunodeficiency Syndrome concluded that the use of pillboxes can improve adherence to treatment and consequently help with viral suppression, as well as being associated with an overall reduction cost of US\$19,000 on treatments [31]. Not surprisingly, studies state that pillboxes should therefore be a standard intervention to improve adherence to antiretroviral therapy and other types of oral medication [25,31-33].

However, management of medication requires a high cognitive level and is a very complex task. The aspects influencing the use of pillboxes by the older adults can be related to the features of the device and to the personal characteristics of users. It is therefore vital to con- sider the presence of tremors, lack of strength in the hands to open the device and poor grip leading to difficulty picking tablets up. Additionally, reduced visual acuity, poor memory and the capacity to program the alarm and fill the empty box must be taken into account when choosing and/or prescribing the pillbox [2,11, 33,34]. In addition, the literature points out that a busy schedule, the complexity of the drug regimen and the difficulty in remembering the right doses are the biggest challenges to adherence [11,18,24].

Visual acuity, contrast sensitivity and stereopsis should be considered potential risk factors for impaired ability to implement a medication regimen in older adults [35]. As such, pillbox characteristics such as a lack of contrast between letters and the background (container color), inadequate opening/closing mechanism, small compartments in relation to the size and number of tablets to be used, shape of the device, alarm systems being difficult to use, lack of security, and lack of a separation between medication to be taken before and after breakfast are all important.

The results suggest that these devices can be useful for organizing medication when they are adequately distributed to patients, taking into account factors such as posology and the user-related visual, motor and cognitive abilities when a device is chosen [33]. It was therefore observed that pillboxes should be designed to take into account factors related to users, including sensory and neural-muscle-skeletal changes, modifications that could help the elderly population in this task. For example, the design could include a contrast between letters and container color, an easier opening mechanism [2,33], more adequately sized compartments and better electronic resources, with less complex alarm systems and bigger display screens, that would improve safety when performing this task.

In Pillbox 6 and Pillbox 2, those medications to be taken on an empty stomach were mixed together with all the pills to be taken after breakfast. Inclusion of a fifth compartment for medication to be taken while fasting was suggested by one of the participants. This is a modification that could increase the efficiency of these devices.

It is clear that poorly designed devices can lead to mistakes and contribute to non-adherence to prescriptions; thus, due to the great heterogeneity of these population, there is no universal pillbox and each and every aspect cited above needs to be considered when a pillbox is prescribed [24,33].

By the amount of participants who wished to continue to use the pillboxes after the end of the study, it can be said that these devices are seen as useful by them. According to an American study, pillboxes are ranked the most helpful by the patients who selected to use some 
kind of medication reminder tools [24].

In this way, one can observe that the pillboxes are a simple, low-cost way to intervene in difficult to adhere to a drug treatment, but that still requires further studies in relation to the difficulties presented by the older adults while using them $[24,25]$.

\section{CONCLUSION}

This research could contribute significantly to the understanding of the difficulties faced by the elderly population in managing their medications while using pillboxes. It could also help practitioners, caregivers and families to make an evaluation of the assistive resources available and the best choices to improve the functionality of the older adults and help them to keep their independence in instrumental activities of daily life. This technology coupled with other reminder tools like timers, calendar stickers and text message reminders might help a wide-ranging spectrum of poorly adherent patients to obtain a near optimal disease management. Further studies are necessary, covering a large sample size and including frail and very old persons with different levels of functionality.

\section{ACKNOWLEDGEMENTS}

This project was supported by a research grant from the Dean of Research-São Paulo University. We would like to thank Vanessa S. M. Eisenhut for her help during the data collection and Ursula Houston for the revision of the English version of the manuscript.

\section{REFERENCES}

[1] Leendertse, A.J., Egberts, A.C., Stoker, L.J. and van den Bemt, P.M. (2008) Frequency of and risk factors for preventable medication-related hospital admissions in the Netherlands. Archives of Internal Medicine, 168, 18901896. http://dx.doi.org/10.1001/archinternmed.2008.3

[2] Stegemann, S., Ecker, F., Maio, M., Kraahs, K., Wohlfart, R., Breitkreutz, J., Zimmer, A., Bar-Shalom, D., Hettrich, P. and Broegmann, B. (2010) Geriatric drug therapy: Neglecting the inevitable majority. Ageing Research Reviews, 9, 384-398. http://dx.doi.org/10.1016/j.arr.2010.04.005

[3] Coons, S.J., Sheahan, S.L., Martin, S.S., Hendricks, J., Robbins, C.A. and Johnson, J.A. (1994) Predictors of medication noncompliance in a sample of older adults. Clinical Therapeutics, 16, 110-117.

[4] Leendertse, A.J., Visser, D., Egberts, A.C. and van den Bemt, P.M. (2010) The relationship between study characteristics and the prevalence of medication-related hospitalizations: A literature review and novel analysis. Drug Safety, 33, 233-244. http://dx.doi.org/10.2165/11319030-000000000-00000

[5] Zed, P.J., Abu-Laban, R.B., Balen, R.M., Loewen, P.S., Hohl, C.M., Brabacher, J.R., Wilbur, K., Wiens, M.O., Samoy, L.J., Lacaria, K. and Purssell, R.A. (2008) Inci- dence, severity and preventability of medication-related visits to the emergency department: A prospective study. Canadian Medical Association Journal, 178, 1563-1569. http://dx.doi.org/10.1503/cmaj.071594

[6] Binkley, K.N., McConnell, K.J., Slater, A.R. and Walden, G.B. (2007) Adverse drug reaction reduction and medication tracking system. Proceedings of ENGG 3100: Design III projects, Guelph, 37-38.

[7] Field, T.S., Mazor, K.M., Briesacher, B., Debellis, K.R. and Gurwitz, J.H. (2007) Adverse drug events resulting from patient errors in older adults. Journal of the American Geriatrics Society, 55, 271-276. http://dx.doi.org/10.1111/j.1532-5415.2007.01047.x

[8] Vaur, L., Vaisse, B., Genes, N., Elkik, F., Legrand, C. and Poggi, L. (1999) Use of electronic pill boxes to assess risk of poor treatment compliance: Results of a largescale trial. American Journal of Hypertension, 12, 374380. http://dx.doi.org/10.1016/S0895-7061(98)00274-X

[9] Hayes, T.L., Larimer, N., Adami, A. and Kaye, J.A. (2009) Medication adherence in healthy elders: Small cognitive changes make a big difference. Journal of Aging and Health, 21, 567-580.

http://dx.doi.org/10.1177/0898264309332836

[10] Ho, M., Bryson, C.L. and Rumsfeld, J.S. (2009) Medication adherence: Its importance in cardiovascular outcomes. Circulation, 119, 3028-3035.

http://dx.doi.org/10.1161/CIRCULATIONAHA.108.7689 $\underline{86}$

[11] Zartman, A.L., Hilsabeck, R.C., Guarnaccia, C.A. and Houtz, A. (2013) The pillbox test: An ecological measure of executive functioning and estimate of medication management abilities. Archives of Clinical Neuropsychology, 28, 307-319.

http://dx.doi.org/10.1093/arclin/act014

[12] Hayes, T.L., Cobbinah, K., Dishongh, T., Kaye, J.A., Kimel, J., Labhard, M., Leen, T., Lundell, J., Ozertem, U., Pavel, M., Philipose, M, Rhodes, K. and Vurgun, S. (2009) A study of medication-taking and unobtrusive, intelligent reminding. Telemedicine Journal and E-Health, 15, 770776. http://dx.doi.org/10.1089/tmj.2009.0033

[13] Duca, G.F.D., Silva, M.C. and Hallal, P.C. (2009) Disability relating to basic and instrumental activities of daily living among elderly subjects. Revista de Saúde Pública, 43, 796-805. http://dx.doi.org/10.1590/S0034-89102009005000057

[14] Lima, M.G., Barros, M.B., César, C.L., Goldbaum, M., Carandina, L. and Ciconelli, R.M. (2009) Impact of chronic disease on quality of life among the elderly in the state of São Paulo, Brazil: A population-based study. Revista Panamericana de Salud Pública, 25, 314-321. http://dx.doi.org/10.1590/S1020-49892009000400005

[15] Hubbard, T. and McNeill, N. (2012) Thinking outside the pillbox-Improving medication adherence and reducing readmissions. New England Health Institute, Cambridge. http://www.nehi.net/publications/76/thinking_outside_the _pillbox_improving_medication_adherence_and_reducin g_readmissions

[16] Mizokani, F., Koide, Y., Noro, T. and Furuta, K. (2012) Polypharmacy with common diseases in hospitalized eld- 
erly patients. American Journal of Geriatric Pharmacotherapy, 10, 123-128. http://dx.doi.org/10.1016/j.amjopharm.2012.02.003

[17] Watson, R. (2008) Research into ageing and older people. American Journal of Nursing Management, 16, 99-104. http://dx.doi.org/10.1111/j.1365-2834.2007.00834.x

[18] O’Connor, D.M., Savageau, J.A., Centerbar, D.B., Wamback, K.N., Ingle, J.S. and Lomerson, N.J. (2009) Lesson in a pill box: Teaching about the challenges of medication adherence. Family Medicine Journal, 41, 99-104.

[19] Insel, K., Morrow, D., Brewer, B. and Figueredo, A. (2006) Executive function, working memory, and medication adherence among older adults. The Journals of Gerontology: Series B, 61, 102-107. http://dx.doi.org/10.1093/geronb/61.2.P102

[20] Corsonello, A., Pedone, C. and Incalzi, R.A. (2010) Agerelated pharmacokinetic and pharmacodynamic changes and related risk of adverse drug reactions. Current $\mathrm{Me-}$ dicinal Chemistry, 17, 571-584.

http://dx.doi.org/10.2174/092986710790416326

[21] Gould, O.N., Todd, L. and Irvine-Meek, J. (2009) Adherence devices in a community sample: How are pillboxes used? Canadian Pharmacists Journal, 142, 28-35. http://dx.doi.org/10.3821/1913-701X-142.1.28

[22] Holmes, J. (2010) Take your medicine-A guide to pill boxes, dispensers and reminders. Cartwheel, London. http://www.rica.org.uk/sites/default/files/documents/pdfs/ home-tech/medicine-dispensers.pdf

[23] Naditz, A. (2008) Medication compliance-Helping patients through technology: Modern "smart" pillboxes keep memory-short patients on their medical regimen. Telemedicine Journal and E-Health, 14, 875-880. http://dx.doi.org/10.1089/tmj.2008.8476

[24] Rife, K.M., Ginty, S.E., Hohner, E.M., Stamper, H.R., Sobota, K.F. and Bright, D.R. (2012) Remember your meds: Medication education delivers success. Innovations in Pharmacy, 3, 1-6.

[25] Valenciano, I.E., Teller, J.M.C., Orbis, I.C., Muñoz, C.G., Angora, M.C. and Piquero, J.M.F. (2013) OHP-025 drug information and the use of a pillbox to improve satisfaction of patients treated with Temozolomide. European Journal of Hospital Pharmacy: Science and Practice, 20, A144-A145. http://dx.doi.org/10.1136/ejhpharm-2013-000276.399

[26] Raehl, C.L., Bond, C.A., Woods, T., Patry, R.A. and Sleeper, R.B. (2002) Individualized drug use assessment in the elderly. Pharmacology, 22, 1239-1248. http://dx.doi.org/10.1592/phco.22.15.1239.33473

[27] Lau, D.T., Briesacher, B.A., Mercaldo, N.D., Halpern, L., Osterberg, E.C., Jarzebowski, M., McKoy, J.M. and Ma- zor, K. (2008) Older patients' perceptions of medication importance and worth: An exploratory pilot study. Drugs \& Aging, 25, 1061-1075. http://dx.doi.org/10.2165/0002512-200825120-00007

[28] Barat, I., Andreasen, F. and Damsgaard, E.M.S. (2001) Drug therapy in the elderly: What doctors believe and patients actually do. British Journal of Clinical Pharmacology, 51, 615-622. http://dx.doi.org/10.1046/j.0306-5251.2001.01401.x

[29] Suárez-Varela, M.T.M., Baena, A.V., Riu, P.P., Carnero, M.M.A., Alvarez, E.H., Merino, R.E., Domínguez, P.E., Gutiérrez, D.R., Marín, P.V., Palma C.R., Luque, A.M., Morales, S.L., Ramírez, M.J., Ceballos, J.M.G., Trujillo, A.P., Pareja, F.C., Rayo, M.J.M, Lopez, M.D.A., López, A.P., Montoya, I.R., Jiménez, V.N., Cerezo, M.I.H., Gálvez, D.G., Jiménez, M.C.M., Misas, A.M.M., Estebas, J.A.H., Gómez, J.R., Sánchez, M.T.R. and Huertas, P.G. (2009) Study on the use of a smart pillbox to improve treatment compliance. Atención Primaria, 41, 185-191. http://dx.doi.org/10.1016/j.aprim.2008.07.003

[30] Conner, J., Rafter, N. and Rogers, A. (2004) Do fixeddose combination pills or unit-of-use packaging improve adherence? A systematic review. Bulletin of the World Health Organization, 82, 935-939.

[31] Petersen, M.L., Wang, Y., van der Lann, M.J., Guzman, D., Riley, E. and Bangsberg, D.R. (2007) Pillbox organizers are associated with improved adherence to HIV antiretroviral therapy and viral suppression: A marginal structural model analysis. Clinical Infectious Diseases, 45, 908-915. http://dx.doi.org/10.1086/521250

[32] Golin, C.E., Liu, H., Hays, R.D., Miller, L.G., Beck, C.K., Ickovics, J., Kaplan, A.H. and Wenger, N.S. (2002) A prospective study of predictors of adherence to combination antiretroviral medication. Journal of General Internal Medicine, 17, 756-765. http://dx.doi.org/10.1046/j.1525-1497.2002.11214.x

[33] Palen, L. and Aaløkke, S. (2011) Of pill boxes and piano benches: "Home-made" methods for managing medication. Proceedings of Computer Supported Cooperative Work '06, New York, 79-88. http://dx.doi.org/10.1145/1180875.1180888

[34] Lam, A.Y., Anderson, K., Borson, S. and Smith, F.L. (2011) A pilot study to assess cognition and pillbox fill accuracy by community-dwelling older adults. Consultant Pharmacist, 26, 256-263. http://dx.doi.org/10.4140/TCP.n.2011.256

[35] Windham, B.G., Griswold, M.E., Fried, L.P., Rubin, G.S., Xue, Q.L. and Carlson, M.C. (2005) Impaired vision and the ability to take medications. Journal of the American Geriatrics Society, 53, 1179-1190. 